\title{
Conservative treatment of duodenal diverticulitis perforation: a case report and literature review
}

This article was published in the following Dove Press journal: Open Access Emergency Medicine

\section{Ki Hoon Kim' \\ Sang Hyun Park ${ }^{2}$}

'Department of Surgery, Haeundae Paik Hospital, Inje University College of Medicine, Busan, South Korea; ${ }^{2}$ Department of Urology, Haeundae Paik Hospital, Inje University College of Medicine, Busan, South Korea
Correspondence: Ki Hoon Kim Department of Surgery, Haeundae Paik Hospital, Inje University College of Medicine, I435, Jwa-dong, Haeundae-gu, Busan 612-030, South Korea

$\mathrm{Tel}+825 \mathrm{I} 7970260$

Fax +82 5I 7970276

Email medhun@hanmail.net

\begin{abstract}
Perforation is the rarest complication of the duodenal diverticulum (DD), but it is the most serious complication. Mortality rate was reported up to $30 \%$, which may be related to diagnostic delay because the symptoms of the perforated DD are vague and nonspecific. Therefore, accurate diagnosis is important to improve the clinical outcome. Surgical treatment was considered as the standard therapeutic option. However, surgical intervention may increase morbidity and mortality due to surgical complications. Therefore, nonoperative management can be considered in some patients with perforated diverticulum who have stable vital signs without generalized peritonitis, or in elderly patients with comorbidities. Several case reports of nonoperative management of perforated DD have been reported. Herein, we describe a patient with perforated DD diagnosed based on a computed tomography scan, who was successfully treated with conservative treatment.
\end{abstract}

Keywords: duodenal diverticulum, perforated duodenal diverticulum, nonoperative management

\section{Introduction}

The prevalence of duodenal diverticulum (DD) has been found to be as high as $22 \%$ in autopsy series; ${ }^{1}$ however, most cases are asymptomatic. DD can be diagnosed when a diverticula-related complication develops. Perforation is a rare complication; however, it is the most serious complication of DD and associated with a mortality rate of up to $30 \% .^{2}$ Choosing the proper treatment is most important, and physicians are faced with the problem of deciding which treatment to perform. Surgical management as the treatment of perforated DD has been selected according to many published case reports. ${ }^{3-5}$ However, surgical intervention may increase morbidity and mortality due to surgical complications, such as bile duct injury, pancreatitis, duodenal leak, or fistula, abscess, and persistent sepsis. Therefore, nonoperative management can be considered in some patients with perforated diverticulum who have stable vital signs without generalized peritonitis or in elderly patients with comorbidities. ${ }^{6}$ Several case reports of nonoperative management of perforated DD have been reported. ${ }^{7,8}$ Herein, we describe a patient with perforated DD diagnosed based on a computed tomography (CT) scan, who was successfully treated with conservative treatment.

\section{Case report}

A 68-year-old man presented to the emergency department with a 4-day history of abdominal pain. He described a sharp pain in the right upper abdomen and epigastrium 
that developed after eating, and he had dull pain in the middle of his upper back. Four hours before admission, the pain became more severe. Additionally, he began to have fever, chills, and vomiting. On arrival, his vital signs were as follows: body temperature, $40.2^{\circ} \mathrm{C}$; heart rate, 90 beats/ min; blood pressure, $140 / 80 \mathrm{mmHg}$; and respiratory rate, 20 breaths/min. The physical examination revealed pain on palpation of the right upper abdomen and epigastrium without signs of peritoneal irritation. Blood test results showed the following: white blood cell count, 11,240 cells $/ \mu \mathrm{L}$; C-reactive protein (CRP) level, $23.33 \mathrm{mg} / \mathrm{dL}$; procalcitonin (PCT) level, $1.88 \mathrm{ng} / \mathrm{mL}$; and interleukin-6 level, $30.3 \mathrm{pg} / \mathrm{mL}$. Abdominal CT was performed, and the scan showed loculated fluid collection with abundant air bubbles around the second and third portions of the duodenum in the anterior pararenal space (Figure 1). He was admitted because of suspected DD perforation and received intravenous broad-spectrum antibiotics (piperacillin/tazobactam [4.5 g every 6 hours for 10 days] and metronidazole [500 mg every 8 hours for 5 days]) and bowel rest initially. After conservative treatment, his clinical

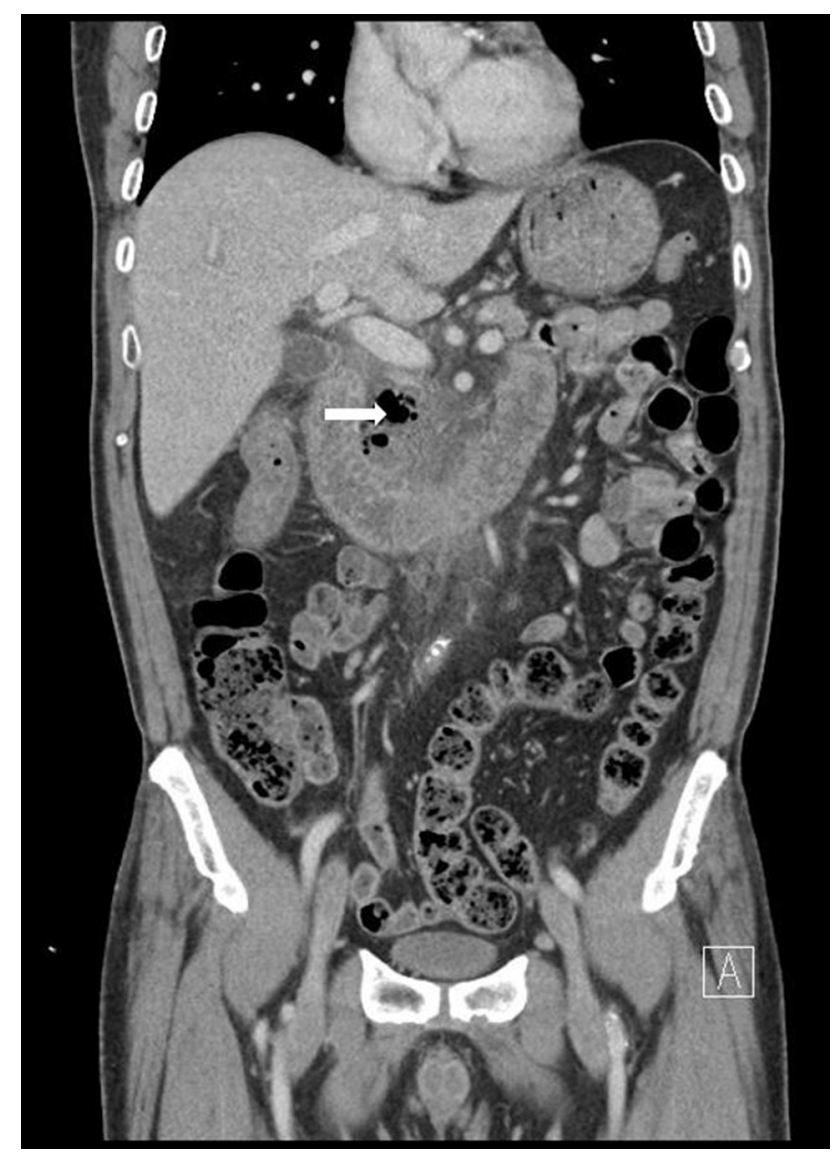

Figure I Abdominal CT showing loculated fluid collection with abundant air bubbles (white arrow) around duodenal second and third portions in anterior pararenal space.

Abbreviation: $\mathrm{CT}$, computed tomography. conditions improved and the laboratory findings improved. He received total parenteral nutrition and continued nothing by mouth. He had an uneventful clinical course. On the seventh hospital day, follow-up CT was performed. The CT scan showed improvement in edematous duodenal wall thickness and loculated fluid collection, but air bubbles remained around the second portion of the duodenum. Therefore, we decided to maintain conservative management. On the 14 th hospital day, the follow-up CT scan showed the near complete resolution of perforated DD (Figure 2). The patient's oral intake of food and drink started with sips of water and gradually proceeded to diet. He was discharged on hospital day 17 without complications. Two weeks later, he did not complain of any symptoms in the outpatient clinic.

\section{Ethical statement}

Written informed consent had been obtained from patient for the publication of this case report and accompanying images.

\section{Discussion}

Perforation of the DD is the rarest but most serious complication of the diverticulum. The most common causes of perforation are diverticulitis, enterolithiasis, ulceration, and

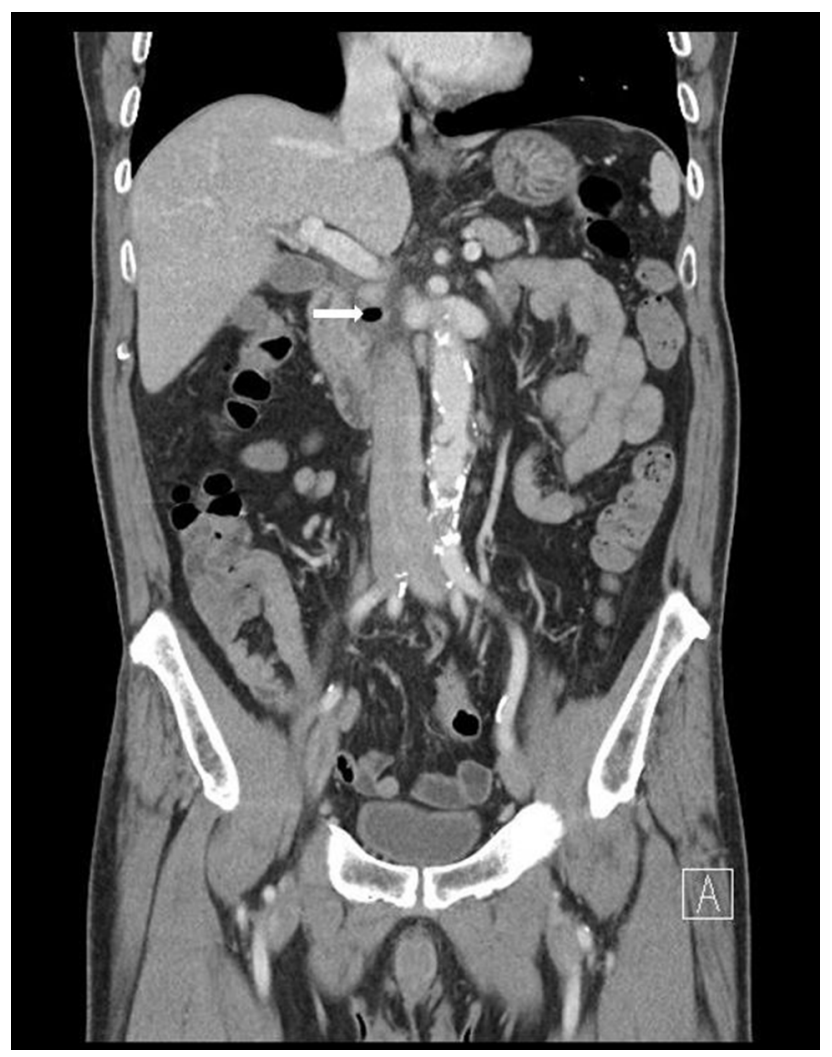

Figure 2 Abdominal CT showing decreased loculated fluid collection with air bubbles (white arrow) around duodenal second portion.

Abbreviation: CT, computed tomography. 
foreign bodies. ${ }^{9}$ Acute symptoms associated with gastrointestinal (GI) tract perforation depend on the nature and location of the GI spillage. The duodenum is mostly located in the retroperitoneum, and the DD is mostly present in the second portion of the duodenum. The DD usually perforates the retroperitoneum, and the presentation of this condition may be subtler and thus be difficult to diagnose because of the lack of generalized peritonitis. ${ }^{10}$ Therefore, a patient's abdominal examination can be relatively normal initially or reveal only mild focal tenderness, as in the case of contained or retroperitoneal perforation. Retroperitoneal GI tract perforation often leads to back pain due to the anatomical location, and sometimes diverticular perforation presents with acute pain, followed by nausea and vomiting. ${ }^{11}$ Generally, compared to other complications of the diverticulum, diverticular perforation most often requires operation. Preferentially, surgical intervention should be considered in unstable patients (eg, those diagnosed as having panperitonitis or a septic condition and patients who do not show rapid improvement with nonoperative management). However, morbidity and mortality might increase in patients who receive surgical treatment because of the occurrence of surgical complications, eg, bile duct injury, pancreatitis, fistula, abscess, and persistent sepsis. If a patient's vital status is stable and perforation occurs without evidence of gross contamination, conservative treatment can be chosen initially. ${ }^{8}$ For example, diverticular microperforation, ie, contained perforation, which is only evident by the presence of air bubbles outside of the bowel wall on an abdominal CT scan, can be treated with intravenous antibiotics and bowel rest in a manner similar to that for patients with uncomplicated diverticulitis. Close clinical observation and frequent physical examinations should be performed to detect the evidence of disease progression. Additionally, serial follow-up examinations of inflammatory markers, eg, the complete blood count, CRP level, and PCT level, might be helpful when providing conservative treatment. The CRP level increases in acute diverticulitis and correlates with the severity of diverticulitis. Käser et $\mathrm{al}^{12}$ found that a high CRP level is a strong indicator of diverticulitis perforation. In addition, Ridgway et al $^{13}$ suggested that the CRP level was strongly correlated with the resolution of symptoms and to be a marker for assessing the response to conservative treatment. Several studies have mentioned the advantage of using the PCT level as a biomarker of infection because it rapidly increases and reaches its peak within a very short time. ${ }^{14,15}$ Moreover, if the patient responds appropriately to the treatment, the PCT level returns to normal range faster. In our patient, the CRP and PCT levels were high initially; however, they returned to normal levels as the treatment progressed. The PCT level in combination with other biomarkers might be helpful tools to detect the patient's response to conservative treatment. Furthermore, if abdominal CT, which has helped improve the diagnosis of diverticulitis, is performed repeatedly, it can be helpful in predicting the outcome of treatment since it can be used to confirm resolution of the inflammatory process.

Surgical treatment is warranted for stable patients who do not show rapid improvement with conservative treatment and unstable patients with signs of diffuse peritonitis due to perforation. The standard operative treatment option is diverticulectomy, followed by simple closure of the site. Occasionally, simple intra-abdominal drainage is only performed at the site of abscess formation, but if substantial duodenal or retroperitoneal inflammation is present, a more complex procedure (eg, duodenal diversion, pyloric exclusion, gastro-enteric anastomosis, tube duodenostomy, and segmental duodenal resection or even pylorus-preserving Whipple) might be adequate. ${ }^{16}$

\section{Conclusion}

Conservative treatment may be useful in patients with earlystage perforated DD who have a good general condition without impending sepsis. Serial inflammatory markers at follow-up examinations and repeated CT are required to monitor the progression of inflammation. Surgical treatment is warranted when disease progression does not show rapid improvement with conservative management or the patient's status is unstable because of perforation.

\section{Author contributions}

All authors contributed toward data analysis, drafting and revising the paper and agree to be accountable for all aspects of the work.

\section{Disclosure}

The authors report no conflicts of interest in this work.

\section{References}

1. Ackermann W. Diverticula and variations of the duodenum. Ann Surg. 1943;117(3):403-413.

2. Bergman S, Koumanis J, Stein LA, Barkun JS, Paraskevas S. Duodenal diverticulum with retroperitoneal perforation. Can J Surg $2005 ; 48(4): 332$.

3. Schnueriger B, Vorburger SA, Banz VM, Schoepfer AM, Candinas D. Diagnosis and management of the symptomatic duodenal diverticulum: a case series and a short review of the literature. J Gastrointest Surg. 2008;12(9):1571-1576. 
4. Haboubi D, Thapar A, Bhan C, Oshowo A. Perforated duodenal diverticulae: importance for the surgeon and gastroenterologist. BMJ Case Rep. 2014;2014:bcr2014205859.

5. Mathis KL, Farley DR. Operative management of symptomatic duodenal diverticula. Am J Surg. 2007;193(3):305-309.

6. Oukachbi N, Brouzes S. Management of complicated duodenal diverticula. J Visc Surg. 2013;150(3):173-179.

7. Thorson CM, Paz Ruiz PS, Roeder RA, Sleeman D, Casillas VJ. The perforated duodenal diverticulum. Arch Surg. 2012;147(1):81-88.

8. Martinez-Cecilia D, Arjona-Sanchez A, Gomez-Alvarez M, et al. Conservative management of perforated duodenal diverticulum: a case report and review of the literature. World J Gastroenterol. 2008;14(12):1949-1951.

9. Sanjay KM, Rajesh K, Upender KC, Jatinder M, Satinder SM. Duodenal diverticulum: Review of literature. Indian J Surg. 2004;66:140-145.

10. Dennesen PJ, Rijken J. Duodenal diverticulitis. Neth $\mathrm{J}$ Med. 1997;50(6):250-253.
11. Rossetti A, Christian BN, Pascal B, Stephane D, Philippe M. Perforated duodenal diverticulum, a rare complication of a common pathology: A seven-patient case series. World J Gastrointest Surg. 2013;5(3):47-50.

12. Käser SA, Fankhauser G, Glauser PM, Toia D, Maurer CA. Diagnostic value of inflammation markers in predicting perforation in acute sigmoid diverticulitis. World J Surg. 2010;34(11):2717-2722.

13. Ridgway PF, Latif A, Shabbir J, et al. Randomized controlled trial of oral vs intravenous therapy for the clinically diagnosed acute uncomplicated diverticulitis. Colorectal Dis. 2009;11(9):941-946.

14. Dominquez-Comesana E, Ballinas-Miranda J. Procalcitonin as a marker of intraabdominal infection. Cir Cir. 2014;82:197-204.

15. Schuetz $\mathrm{P}, \mathrm{Albrich} \mathrm{W}$, Mueller B. Procalcitonin for diagnosis of infection and guide to antibiotic decisions: past, present and future. BMC Med. 2011;9:107.

16. Costa Simões V, Santos B, Magalhães S, Faria G, Sousa Silva D, Davide J. Perforated duodenal diverticulum: Surgical treatment and literature review. Int J Surg Case Rep. 2014;5(8):547-550.
Open Access Emergency Medicine

\section{Publish your work in this journal}

The Open Access Emergency Medicine is an international, peerreviewed, open access journal publishing original research, reports, editorials, reviews and commentaries on all aspects of emergency medicine. The manuscript management system is completely online and includes a very quick and fair peer-review system, which is all
Dovepress

easy to use. Visit http://www.dovepress.com/testimonials.php to read real quotes from published authors. 